\title{
Breast cancer risk scores in a standard screening population
}

Leila Eadie', Louise Enfield², Paul Taylor ${ }^{3}$, Mike Michell ${ }^{4} \&$ Adam Gibson*2

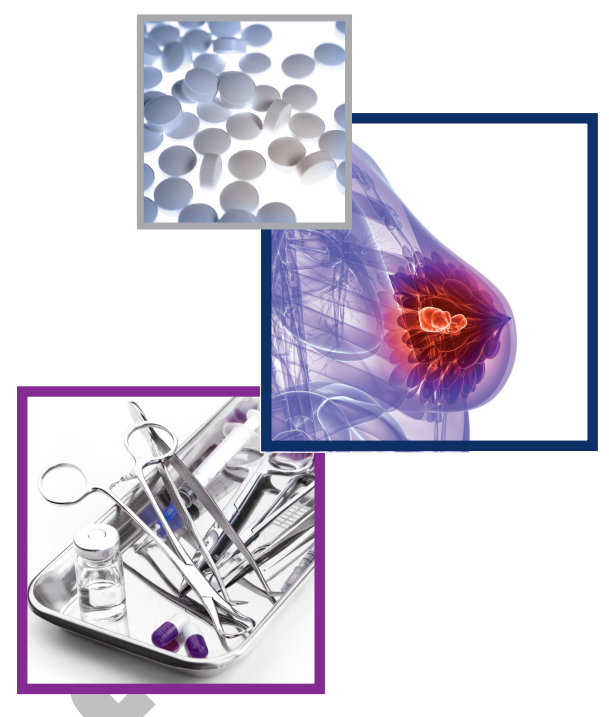

- Breast cancer risk factors \& models

- The three greatest risk factors for breast cancer are gender, aging and family history, as well as genetic factors in certain women.

- A number of models have been proposed for predicting risk. The most well known is the Gail model.

- We have studied the range of risk factors in a standard screening population of women in London.

- Demographics

- The ethnicity of the sample population was highly heterogeneous, but comparable to the population at large.

- Almost a third of participants had a relative with breast cancer.

- 26 out of 355 women were recalled for further investigation.

- Risk scores

- In our sample, the mean 5-year risk score according to the modified Gail model was 1.5\%; the lifetime risk score was $9 \%$.

- Risk factors \& the potential for modification

- A substantial proportion of the women reported modifiable risk factors ( $23 \%$ with current or previous daily alcohol consumption; $58 \%$ were overweight or obese; $44 \%$ with current or previous daily smoking).

- Implications for clinical practice, research \& policy

- Knowledge of risk factors could lead to more personalized care, including advice on reducing risk factors, personalized screening regimes and preventative medication.

SUMMARY Aim: Information regarding the characteristics and breast cancer risk factors of British women in the standard population attending breast cancer screening is limited. Such information could be useful in personalizing screening and care, and informing and educating women about their risk. Materials \& methods: Information about various breast cancer risk factors was obtained from 355 women aged between 46 and 74 years at a UK

'Centre for Rural Health, Aberdeen University, UK

${ }^{2}$ Department of Medical Physics \& Bioengineering, University College London, London, WC1E 6BT, UK

${ }^{3}$ Centre for Health Informatics \& Multiprofessional Education, University College London, London, N19 5LW, UK

${ }^{4}$ South East London Breast Screening Programme, Breast Radiology, King's College Hospital London, SE5 9RS, UK

*Author for correspondence: adam.gibson@ucl.ac.uk

Future

Medicine $\%$ part of 
inner-city breast cancer screening clinic using questionnaires. The risk of breast cancer was calculated using the modified Gail model and analyzed using descriptive and regression statistics. Results: There were 26 women recalled for further assessment and two cases confirmed as invasive breast cancer. Forty-seven women reported first-degree relatives with breast cancer. A total of $58 \%$ of our sample was overweight or obese, although $84 \%$ reported meeting the recommended target of $\geq 150$ min of exercise per week. A total of $44 \%$ were smokers and $23 \%$ reported consuming alcohol on a regular basis. The mean lifetime risk score was $9.0 \%$ and the mean 5 -year risk score was $1.5 \%$. Various non-Gail model risk factors were found to be correlated with risk scores, but the only factor that was significantly different between women recalled for further assessment and those who were not was age of menarche. Conclusion: The results suggest that determining risk factor data in a standard screening population could be useful both to the women, who may have modifiable lifestyle factors that can be changed to improve their risk, and to the clinics, which can identify women at a higher risk who may be unaware and not present themselves as candidates for risk assessment.

Breast cancer (BC) screening is currently a hotly debated topic, with controversy about the benefits, harms and scheduling of mammograms [1]; guidelines attempting to alter the frequency of screening or the age groups covered by programs in America produced alarm and outrage [2]. Problems such as false-positive results and overdiagnosis are frequently debated: they result in anxiety, stress and often physical pain for the women involved, in addition to extra healthcare costs [3]. There is also disagreement about the timing of screening: in the UK, women are screened every 3 years. In America, screening is often annual. The International Agency for Research on Cancer and the European Council Recommendation on Cancer Screening suggest screening every 2 years [4,5].

In the UK, the screening program invites around 2.3 million women aged 50-70 years to have mammograms taken every 3 years, and inclusion of women aged 47-73 years is currently being phased in [101]. Almost 15,000 cancers were detected in the 1.88 million women aged 45 and over screened by the program in 2010-2011 (7.8 cases per 1000 women screened) [6]. Currently, radiologists reviewing screening mammograms to determine whether the patient should be recalled for further tests do not usually take into account patient history or specific risk factors unless the woman in question has a family history of $\mathrm{BC}$ and therefore may be asked to attend a specific 'high-risk' clinic. However, if screening was personalized to individual women using a risk assessment or specific risk factors, this could help refine and optimize the screening system, making it both more appropriate and useful for women and more efficient for the health service. We are therefore interested in investigating risk information, but there is little in the literature to describe the women that make up standard screening populations in the UK. This work describes the population that attended an inner-city screening clinic in terms of their demographics and risk factors.

\section{Breast cancer risk factors \& models}

- Risk factors

Research has associated various factors from a person's life with their risk of developing BC. The three greatest risk factors are gender, aging and family history [7]. Genetic factors account for a further small percentage of BC, and hormonal factors and breast density also affect risk. Knowledge of BC risk could help women assess their screening needs. The major known BC risk factors are summarized in Box 1.

\section{- Risk models}

In 1989, Gail and colleagues published details of a simple calculation using various factors from a woman's history that provided a risk assessment for BC [8]. The factors used were: age at menarche, age at first live birth, number of previous biopsies and number of first-degree relatives with $\mathrm{BC}$, and the scoring system was generated using data from Caucasian American women over 40 years who were screened annually. This model has been used as a basis for ongoing improvements in risk assessment, which have included other factors such as breast density [9], extended family history [10], genetic details such as the $B R C A 1$ and BRCA2 genes with family history of cancer [11] and single-nucleotide polymorphisms associated with $\mathrm{BC}$ [12]. A recent review of $\mathrm{BC}$ risk prediction models found 17 different models, few of which had been validated [13]. 
Currently preferred models are the Gail model for Caucasian women with no family history of breast or ovarian cancer, and the Tyrer-Cuzick model for women with risk factors and some family history $[14,15]$. However, the Tyrer-Cuzick model was created using population risk estimates rather than being based on an actual sample of women, and there are inconsistencies with research results arising from the Gail model [15]. In addition, these models are sensitive to trends in the underlying population rates and cannot be used in different populations without recalibration $[16,17]$. None of the models perform consistently when tested on new data and most have been shown to significantly underestimate risk $[13,18]$.

BC risk factors discovered more recently, including not breastfeeding, obesity, alcohol consumption and breast density, have not been included in these models. Ideally, all the known risk factors should be included, but this is likely to be impractical [19]. Investigations have shown that older models can be improved upon by adding these newer risk factors: including an estimate of mammographic breast density, BMI and a selection of genetic polymorphisms in a Swedish version of the Gail model improved the accuracy from 55 to $62 \%$ [20].

Accurate prediction of risk is becoming increasingly important as preventative medications and differential screening for high-risk women are now being based on risk scores. However, there is a paucity of risk factor data in large contemporary cohorts, which is an important limitation for model validation [16].

\section{- Risk distribution}

Internationally, there are data from the USA and Canada describing screening populations, with average lifetime risks of $8 \%$ and 5-year risks of $1.7 \%[21,22]$. In the UK, the Million Women Study [102] collected various lifestyle information from more than a million women aged 50 or over between 1996 and 2001 and linked this to a number of diseases, including $\mathrm{BC}$, but the authors have not published details about the distribution of risk levels in this large sample of women. Similarly, details are routinely recorded about women diagnosed with BC [23] or those who have died as a result of the disease [24]. In addition, specific groups recognized as underrepresented in screening populations, such as ethnic minorities $[25,26]$ or those who choose not to attend [27], are also of interest. However, only

\section{Box 1. Major risk factors for breast cancer by relative risk grouping}

Relative risk: $1.1-2.0$

- Alcohol consumption [50]

- Ashkenazi Jewish background [51]

- Greater height [52]

- High endogenous estrogen or testosterone [53]

- History of endometrial, ovary or colon cancer [54,55]

- Menarche $<12$ years [56,57]

- Recent oral contraceptive use [58]

- No full-term pregnancies (nulliparous) [59]

- Age at first full-term pregnancy $>30$ years [60]

- No breastfeeding [61]

- Menopause $>55$ years [56,57]

- Postmenopausal obesity/adult weight gain [62]

- Recent and/or long-term use of hormone replacement therapy [63]

Relative risk: 2.1-4.0

- High postmenopausal bone density [64]

- One or two first-degree relatives with breast cancer $[65,66]$

Relative risk: $>4.0$

- Age $>65$ years [67]

- Inherited genetic mutations (BRCA1 and/or BRCA2) [68]

- Mammographically dense breasts [69]

- Atypical hyperplasia [70,71]

- History of breast cancer [72]

- High-dose radiation to chest [73-75]

the recent PROCAS study has collected basic data about risk factors in a UK screening setting and used it to calculate risk levels [28].

\section{- Aims}

This article reports on the range of Gail model $\mathrm{BC}$ risk scores found in a standard screening population in an inner-city clinic. This will be discussed within the context of the UK screening program and within the wider view of national and worldwide BC risk measurement. The study uses a representative sample of women attending the clinics, rather than the positive diagnosis only or a 'cancer-enriched' sample seen in many other studies. We do not intend to generalize findings to other populations, but they will be used to highlight areas where the current UK screening system has potential for improvement. We chose to use the Gail model because it is a well-validated risk algorithm that does not require detailed family history or genetic information.

\section{Methods}

- Location

The study was located within the South East London Breast Screening Service, part of the 
NHS Breast Screening Programme, which provides breast screening for women approximately every 3 years in the London boroughs of Lewisham, Lambeth, Southwark, Bromley, Bexley and Greenwich. The service currently invites more than 200,000 women aged between 47 and 73 years from the region for screening at three static sites and five mobile units every 3 years. The data collection took place in the King's College Hospital breast screening clinic at Denmark Hill, London, where the South East London Breast Screening Service is based, and was approved by the London-Fulham Research Ethics Committee.

\section{- Data collection}

Up to 120 women are invited to be screened in the participating clinic each day, and approximately $50 \%$ of these attend their appointment. All women attending the clinic during the 32-day study period in July to August 2012 were informed about the research on their arrival at the clinic and given the study questionnaire if they provided written consent to participate. This therefore formed a self-selecting convenience sample. The exclusion criteria were:

- Age <18 years;

- English comprehension not sufficient to give informed consent and complete the questionnaire;

- Any other cause of inability to give consent.

Women who had previously had BC were excluded from the Gail model risk calculations, but provided data about the population demographics and the radiologist decision.

The questionnaire comprised eight sections: physical factors (including age, ethnicity, height, weight, bra size); cancer history (including any cancer diagnosis, biopsy, ovary removal); family history (including Jewish ancestry, relatives with $\mathrm{BC}$, genetic testing, risk assessment); smoking and alcohol use; reproductive history (including menstruation history, contraception use, pregnancy and childbearing, breastfeeding); menopause and hormone replacement therapy (HRT; including menopause history, HRT and tamoxifen use, participation in cancer prevention trials); exposure to radiation (including details of any x-rays, CT scans, radiation treatment); and exercise. There were 40 questions in total, the majority having a 'tick-box' style, but many questions were conditional on the answers to previous questions and could be skipped by many participants. We wanted to minimize the time required to complete the questionnaire to encourage women to participate, and had limited researcher support for participants. As such, there were no questions about family composition and only basic details about family history of breast cancer were collected ('have any of your relatives been diagnosed with breast cancer? If yes, which relatives?').

A researcher was present in the clinic to answer questions and provide any assistance required. Risk scores were not provided to participants but details of local risk assessment services were available. Participants also gave consent for the study team to access their mammogram images and the radiologist reports on the images, which formed the 'outcome' measure for this study.

\section{- Data analysis}

The questionnaire data were entered into a spreadsheet and the resulting data checked and cleaned. The modified Gail 5-year risk score (risk of developing invasive breast cancer during the next 5-year period) and lifetime risk score (risk of developing invasive breast cancer up to age 90) used by the US National Cancer Institute's Breast Cancer Risk Assessment Tool [103] were calculated for participants who provided the required information. The original Gail method has been updated to more accurately estimate risk in African-American women (based on the CARE model [29]) and Asian women [30] using amended weightings and interaction factors. The algorithm input includes age at first menstrual period, age at first live birth, number of first-degree relatives (mother, sisters or daughters) who had breast cancer and number of previous benign breast biopsy examinations.

Descriptive statistics were calculated to provide details about the demographics and risk factors of our sample, and linear regression analyses using the 'least squares' method were undertaken to determine which risk factors correlated with the radiologist-reported outcome and the Gail model risk scores. A further comparison was made between women recalled for further testing by the radiologist and those who were not, using the nonparametric MannWhitney $\mathrm{U}$ test to determine differences. A two-tailed significance level of $p=0.05$ with Holm-Bonferroni adjustment was used in these analyses. 


\section{Results}

Questionnaires were returned by 355 women. An average of 59 women attended the clinic each day (range 40-78), so this participation figure represents $9 \%$ of those invited to attend the clinic and $19 \%$ of those who did attend. An additional three women consented to participate but did not return their questionnaires. There were various items of missing data where specific questions were not answered, so sample numbers described below will vary and are defined in each case. Radiologist decisions were available for 346 women with a risk score calculated. There were 26 women recalled for further assessment and of these, 16 had some abnormality found, two of which were confirmed as BC and subsequently underwent surgery. We will not try to compare healthy women with women with $\mathrm{BC}$ because of these small numbers, but we will instead compare risk factors between those who were recalled for assessment and those who were not.

\section{- Physical factors}

Women aged between 47 and 73 years were invited for screening, and the age range of our sample was 46 to 74 years (mean 56.5 years, standard deviation [SD] $6.8 ; \mathrm{n}=348)$. Figure 1 shows the range and spread of participants ages.

The range of height and weight reported were 135-182 cm (mean $163 \pm 7 \mathrm{~cm} ; \mathrm{n}=348)$ and 42-130 kg (mean $71 \pm 15 \mathrm{~kg} ; \mathrm{n}=325)$, respectively. The BMI scores (range $15.8-52.8 \mathrm{~kg} / \mathrm{m}^{2}$; mean $26.8 \pm 5.7 \mathrm{~kg} / \mathrm{m}^{2} ; \mathrm{n}=324$ ) are shown in Figure 2. BMI targets are classified by the WHO [104] and the UK's National Institute for Clinical Excellence as healthy $\left(18.5-24.9 \mathrm{~kg} / \mathrm{m}^{2}\right)$, overweight $\left(25-29.9 \mathrm{~kg} / \mathrm{m}^{2}\right)$ or obese (three different classes by increasing BMI, $\geq 30 \mathrm{~kg} / \mathrm{m}^{2}$ ) [31]. Under this classification, $41 \%$ of our participants were classed as healthy, $32 \%$ were overweight and $26 \%$ were obese.

The questionnaire also asked about bra size as an estimate of breast morphology. The mean chest size was 36 inches $(n=330)$, with the most common cup size (29\% of participants) being 'D', and $72 \%$ having a cup size ' $\mathrm{B}$ ', ' $\mathrm{C}$ ' or ' $\mathrm{D}$ ' $(\mathrm{n}=318)$.

Table 1 compares the ethnic mix of the study population with that of the local area and England as a whole.

\section{- Cancer \& medical history}

Having a previous biopsy to test for $\mathrm{BC}$ is a known risk factor used in the Gail model, and

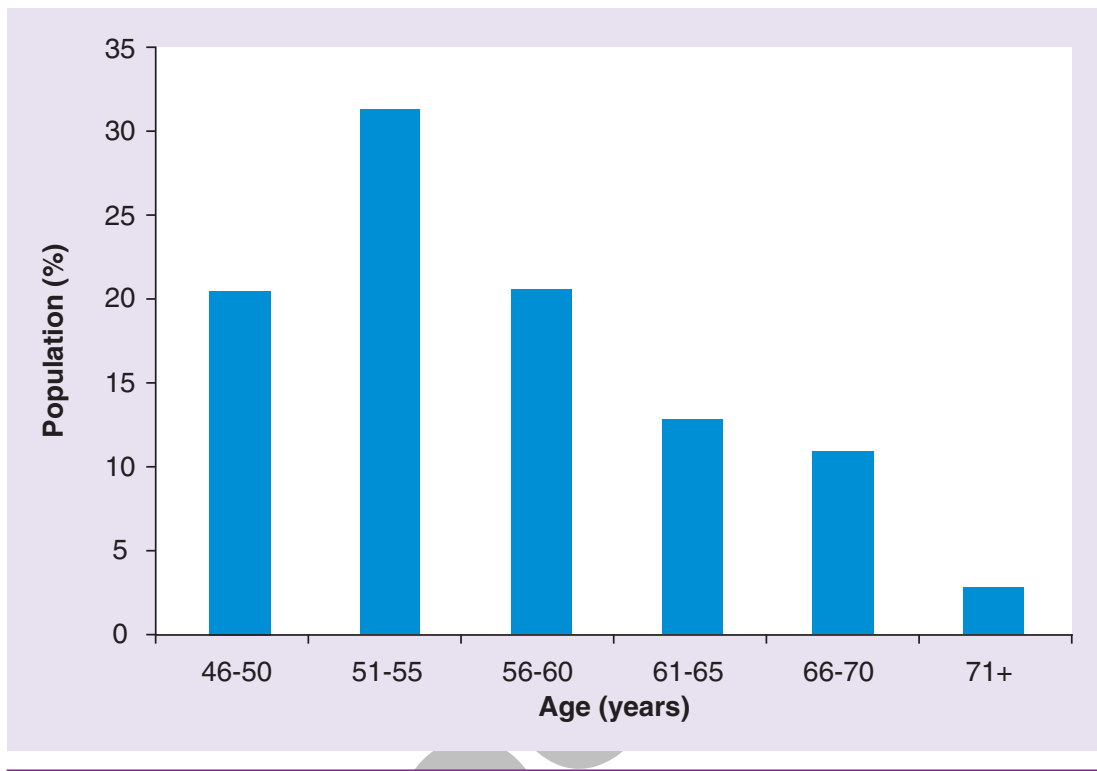

Figure 1. Age groups of participants shown as a percentage of the study population.

54 participants had undergone breast biopsy in the past. The majority of these had just a single previous biopsy, but nine women $3 \%$ of the sample) had had two or more biopsies. Cancer had been previously diagnosed in 28 women ( $8 \%$ of the sample). Participants reported one or more of the following: two ductal carcinoma in situ, seven BC, three ovarian cancer, three cervical cancer, six basal cell carcinoma, and 12 other types of cancer. Fifty-four women (15\% of the sample) had one or both ovaries removed; the reasons included: $37 \%$ due to total hysterectomy, $33 \%$ cysts, $8 \%$ cancer, $6 \%$ fibroids, $8 \%$ ectopic pregnancy and $10 \%$ for other reasons.

\section{- Family history}

A family history of BC can be an indicator of increased risk and 103 participants (29\% of the sample) reported a first- or second-degree relative who had been diagnosed with BC. There were 47 women (13\% of the sample) with first-degree relatives with $\mathrm{BC}$. Two women in the sample had previously had a formal risk assessment performed and one was determined to be at 'moderate' risk. Our risk calculations agreed with this: the Gail model predicted a lifetime risk of $24.7 \%$, a figure at the higher end of the range found. Three women had previously undergone genetic testing, one of which was found to have BRCA1. Furthermore, $10 \%$ of participants had Jewish or eastern European ancestry, which is a risk factor for BC. 


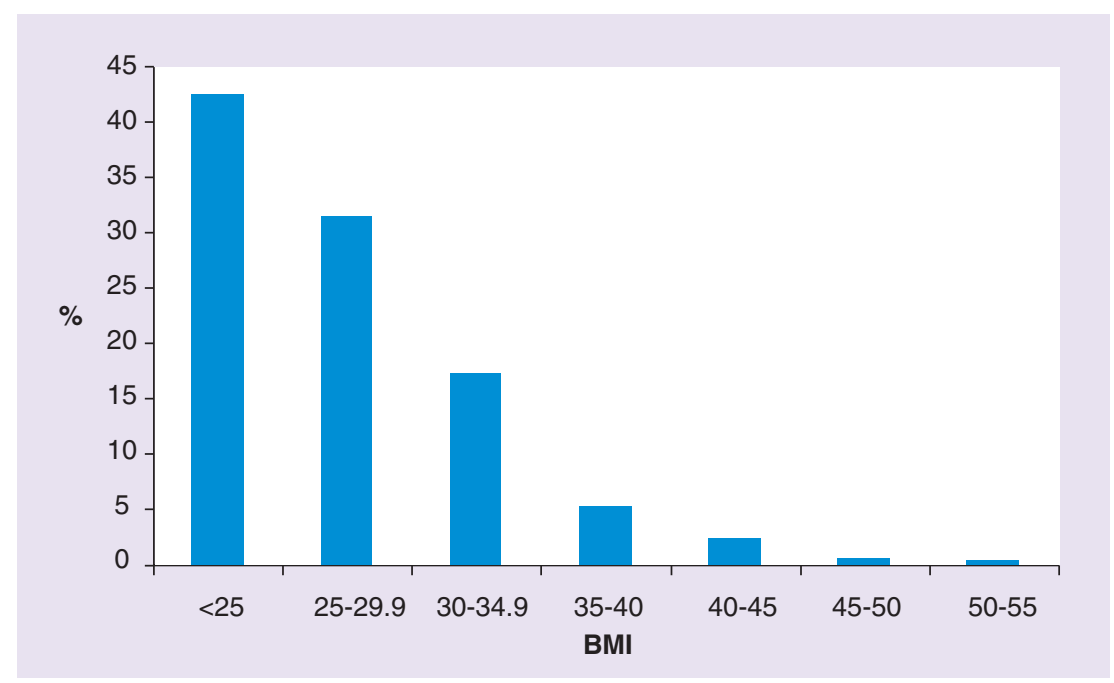

Figure 2. BMI groups of participants shown as a percentage of the study population. with an average age of menarche at $13 \pm 1.9$ years $(\mathrm{n}=345)$. Contraceptive medication had been used in 268 women (e.g., via pill, injection or transdermal patches). A total of 743 pregnancies were reported in 274 women, and these produced 567 children. Participants had their first child at ages ranging from 15 to 41 years, and their last child at ages ranging from 18 to 47 years. Of those who had children, 188 reported breastfeeding, with an average duration of $9 \pm 9$ months (range $1-60$ months; $\mathrm{n}=171$ ).

\section{- Menopause \& HRT}

Two hundred and sixty participants had reached menopause $(74.5 \%$; $n=349)$, with 89 participants being premenopausal or unsure about their menopausal status. $75 \%$ of menopauses had a natural cause, with $25 \%$ being due to surgery ( $73 \%$ of these were as a result of a hysterectomy) or other treatment (e.g., removal of ovaries [6.7\%], HRT [6.7\%], other reason [14\%]).

HRT had been used by 93 participants at some point and was currently being taken by 47 women. The duration of treatment was an average of $85.6 \pm 84$ months (range $1-480$ months; $\mathrm{n}=86$ ).

Four women had used tamoxifen, with one currently taking it. One woman had previously taken part in a double-blind trial on the use of prophylactic tamoxifen.

\section{- Exposure to radiation}

A total of 237 participants reported some exposure to radiation-based imaging: 189 had one or More than $99 \%$ of our sample (349 out of 351 participants) reported previous menstruation,

\begin{tabular}{|c|c|c|c|c|}
\hline Ethnic group & $\begin{array}{l}\text { Study } \\
\text { population (\%) }\end{array}$ & $\begin{array}{l}\text { Borough of } \\
\text { Southwark (\%) }\end{array}$ & London (\%) & England (\%) \\
\hline \multicolumn{5}{|l|}{ Female: all ages } \\
\hline All persons & 352 & 139,400 & $3,902,400$ & $26,295,200$ \\
\hline White & $257(73)$ & $91,500(65.6)$ & $2,722,800(69.8)$ & $23,079,300(87.8)$ \\
\hline Mixed & $6(1.7)$ & $5300(3.8)$ & $137,200(3.5)$ & $475,500(1.8)$ \\
\hline Asian or Asian British & $7(2)$ & $11,200(8.0)$ & $498,700(12.8)$ & $1,542,900(5.9)$ \\
\hline Black or Black British & $66(18.8)$ & $25,400(18.2)$ & $407,900(10.5)$ & $770,000(2.9)$ \\
\hline Other & $16(4.5)$ & $6100(4.4)$ & $135,700(3.5)$ & $427,500(1.6)$ \\
\hline \multicolumn{5}{|c|}{ Female: age 60 years or above } \\
\hline All persons & 104 & 18,900 & 680,000 & $6,319,000$ \\
\hline White & $82(78.8)$ & $15,100(79.9)$ & $567,500(83.5)$ & $6,051,800(95.8)$ \\
\hline Mixed & $2(1.9)$ & $200(1.1)$ & $6700(1.0)$ & $19,700(0.3)$ \\
\hline Asian or Asian British & $0(0.0)$ & $600(3.2)$ & $50,700(7.5)$ & $136,600(2.2)$ \\
\hline Black or Black British & $13(12.5)$ & $2500(13.2)$ & $42,400(6.2)$ & $78,400(1.2)$ \\
\hline Other & $7(6.7)$ & $500(2.6)$ & $12,600(1.9)$ & $32,500(0.5)$ \\
\hline
\end{tabular}


more x-rays (range 1-20 exams), 67 had barium bowel examinations, and 105 had computed tomography (range 1-50 exams). Fourteen participants reported having radiation treatment (range 1-40 sessions, between ages 5 and 63 years). Of these, one had treatment with radioactive iodine for a thyroid condition, 11 had conventional external beam radiotherapy and two had exposure as children in the 1940 s and 1950s.

\section{- Exercise}

The questionnaire asked participants to recall the number of hours spent exercising per week at different times in their life. Results are shown in Table 2, with the percentage of participants that reported no exercise at these time points.

The UK Department of Health recommends at least $150 \mathrm{~min}$ of exercise per week plus muscle strengthening exercises [105], and almost $84 \%$ of our study participants reported this level of exercise or more per week.

\section{- $\mathrm{BC}$ risk scores}

Lifetime and 5-year risk scores were calculated using the adjusted Gail model [8] for all participants who provided the required information, and histograms showing the range of scores are shown in Figures $3 \& 4$, respectively. It can be seen from Figure 3 that the distribution is roughly similar to the normal distribution that could be expected from a standard screening population. The mean \pm SD lifetime risk score was $9.0 \pm 3.3 \%$, and the mean \pm SD 5 -year risk score was $1.5 \pm 0.7 \%$.

Regression analyses showed that beyond the Gail model factors (age, age at menarche, age at first live birth, number of relatives with BC, number of breast biopsies, ethnicity), other potential risk factors collected were correlated with risk scores. For the lifetime risk score, correlations were found with: ovary removal $(\mathrm{p}<0.05)$, ever drinking $(\mathrm{p}<0.01)$, ever taking contraception $(\mathrm{p}<0.01)$, number of pregnancies $(\mathrm{p}<0.01)$, use and duration of HRT $(\mathrm{p}<0.01)$ and age at menopause $(\mathrm{p}<0.05)$. For the 5 -year risk score, correlations were found with: number of pregnancies $(p<0.05)$, age at the birth of last child $(\mathrm{p}<0.05)$ and age at menopause $(p<0.01)$. Table 3 lists the regression coefficients for the risk variables, with mean risk scores for different variable states.

\section{- Screening outcomes}

Screening mammograms are either determined to be normal or the women are recalled for further assessment. In this study, 26 women (7\%) were recalled. Of these, 22 women had followup imaging with ultrasound, and one also had MRI. Six women (23\%) had a biopsy sample taken. Nine women (35\%) were eventually determined not to have an abnormal diagnosis and one did not attend follow-up. The outcomes for participants recalled for further assessment are shown in Table 4. Table 5 shows how the risk factor data collected in the questionnaire differs between women recalled and those not recalled.

The only significant difference between the population who were recalled for further testing and those who were not was seen in age of menarche: women recalled were significantly older at menarche than those who were not recalled $(\mathrm{p}<0.05)$. This significance remained when Holm's sequential Bonferroni adjustment was made to reduce the chance of a type I error.

\section{Discussion}

London has a highly diverse and constantly changing population. The UK BC screening programme has to cope with this diversity and offer all eligible women appropriate surveillance and care. However, little has been published about the women in the standard screening population and it is possible that if their risk factors and needs were better understood, the screening service could become more efficient and appropriate. This study of women attending breast screening in the borough of Southwark, South London, reported on the range of risk factors and scores present and how these related to screening outcomes. Limitations of this study include the number of participants, which was

Table 2. Hours of exercise per week reported at different ages-mean \pm standard deviation (range), $\mathrm{n}=351$.

\begin{tabular}{lllll} 
Exercise (hours/week) & Teens & Age 20-50 & Age 50+ & Currently \\
Strenuous & $4 \pm 4(0-21)$ & $3 \pm 5(0-40)$ & $2 \pm 4(0-40)$ & $2 \pm 4(0-40)$ \\
Moderate & $5 \pm 4(0-21)$ & $6 \pm 5(0-30)$ & $6 \pm 5(0-35)$ & $6 \pm 4(0-25)$ \\
None (\%) & 23 & 15 & 13 & 7 \\
\hline
\end{tabular}




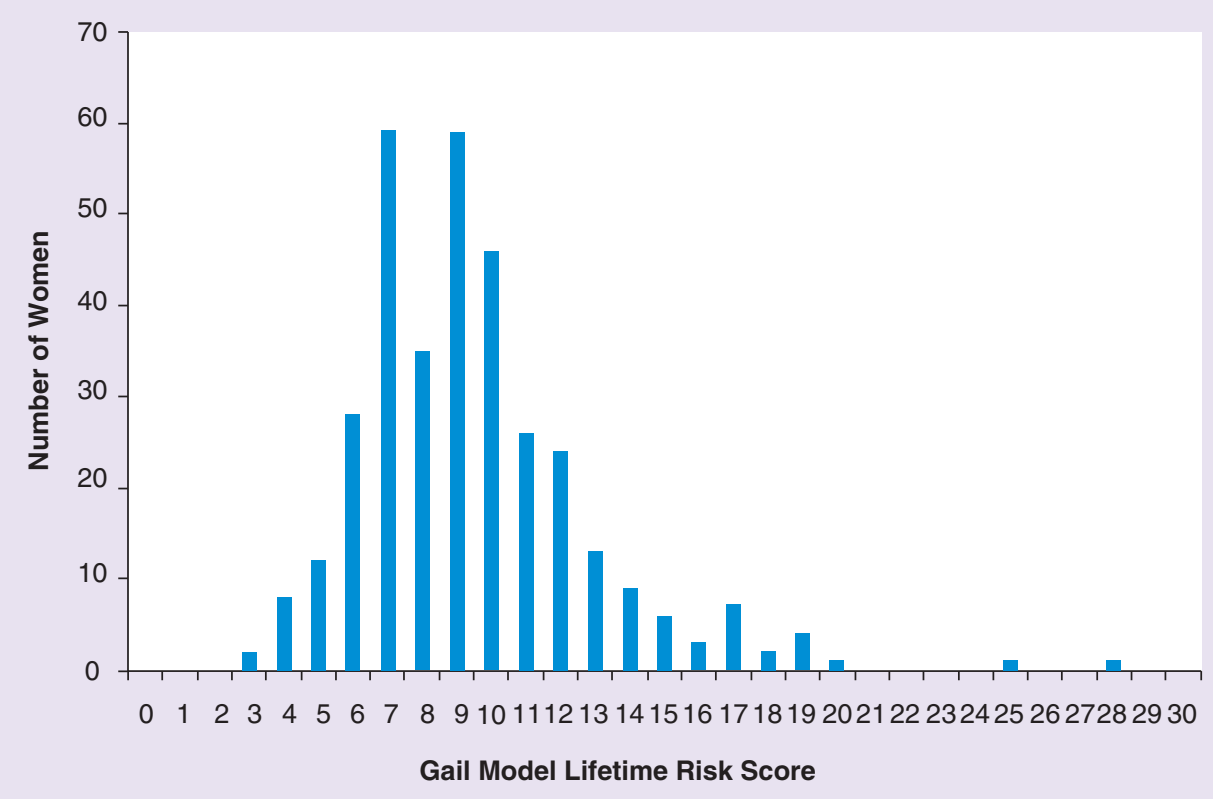

Figure 3. Histogram of the range of lifetime risk scores in the sample.

constrained by the limited time period for data collection. The use of retrospective questionnaire interrogation means that there was likely to be recall bias as participants estimated or guessed at some answers; self-reported assessments of some factors will certainly be underor over-estimated. In addition, many questionnaires did not provide complete data, so the sample numbers vary in the reported results. Finally, we chose the National Cancer Institute's risk assessment tool, based on the Gail model, as a well-validated risk algorithm that did not require comprehensive family history details or any genetic information, and although this is commonly used in the USA to measure risk, other measures are more frequently used in the UK, such as Tyrer-Cuzick or BOADICEA, which are based and focused on genetic aspects of BC. The Tyrer-Cuzick model, for example, requires details about family composition and history of $\mathrm{BC}$ to the level of cousins and nieces, and we decided to forgo this detailed questioning in order to limit the questionnaire to a reasonable time requirement for participants. It is also worth noting that the modified Gail model includes a limited range of ethnicities - for example, although some of the women in our study identified themselves as being from Africa or the Caribbean, they were assessed as 'African-American' as the closest ethnic option, despite potentially having different genetic characteristics. A similar problem was found for women from Japan and Thailand, who were grouped together as 'American-Asian'. Concerns about the applicability of the risk model due to differences in the underlying incidence rates of the USA, where the model was created, and other countries where it might be used [16] are not relevant the UK, where this study was performed, because the reported incidence rates are very similar: in the USA, the rate for Caucasians is 125.4 out of 100,000 [32], which is similar to that reported for England (130.2 out of 100,000$)$ and the UK as a whole $(129.9$ out of 100,000$)$ [33,34]. Incidence rates are slightly lower in South East London (106.5 out of 100,000) [34], but this may be due to the more ethnically mixed population therein - the USA rates are lower for African-Americans (116.1 out of 100,000$)$ and other ethnic groups ( 90 out of 100,000).

\section{- Sample demographics}

The screening clinic hosting this research regularly invites up to 120 women to be screened each day, but only around half of that number actually attend their appointments. We recruited an average of 11 participants per day (range 3-31 women per day) - around a fifth of those attending the clinic each day. There will 
be many reasons why women chose not to participate. Comments from those who declined to take part included concerns about time restrictions (e.g., having to return to work after their appointment), having children with them, and the length of the questionnaire. London reports a low attendance for BC screening, particularly in the inner-city areas, with figures of $63.6 \%$ attendance for Southwark compared with $78.5 \%$ nationally [101]. This low rate is likely due to a variety of factors, including having a mobile and transient population, with often high levels of deprivation and with a more varied ethnic mix than in other areas. In our sample, the white and black ethnicities were slightly over-represented compared with the borough population in general, and Asian women were underrepresented, especially in the $60+$ years age group. This can be compared with the study by Renshaw et al. [26] in which attendance at screening was found to be low for both black and Asian women. Our sample covered the age range invited to screening well: women aged between 47 and 73 are sent appointments, and our sample reported a range of 46-74 years, with an average age of 56 years; $26 \%$ of the sample was aged 60 years or over. Almost a third of our sample (103 women) reported having a relative previously diagnosed with BC. This seems like a high percentage in a standard screening population, but this figure included both first- and second-degree relatives; there were 47 women with first-degree relatives with BC. These numbers may be linked to the participant's choice to attend screening: family illness would inevitably raise disease awareness.

\section{- Risk scores}

The Gail model risk scores calculated estimate the absolute risk, or probability, of developing $\mathrm{BC}$ within the time frame (either 5 years or until the age of 90 for the 'lifetime' estimate). The mean lifetime risk score in our sample, calculated using the adjusted Gail model, was $9.0 \%$ and the mean 5-year risk score was $1.5 \%$. A 5-year score of $\geq 1.7 \%$ and/or a lifetime risk $\geq 20 \%$ indicate higher risk (according to inclusion criteria for the NSABP Breast Cancer Prevention Trial [35] and the American Cancer Society [106], respectively). In our sample, $0.6 \%$ of women $(n=2)$ had a lifetime risk higher than $20 \%$. In terms of 5-year risks, $27 \%(n=95)$ had risk higher than $1.7,3.5 \%(n=12)$ had risk greater than 3 , and $0.6 \%(n=2)$ had risk greater than $5 \%$. This suggests that there are several women in our sample who might be eligible for and benefit from enhanced screening.

The results found in this study can be compared with those found in other studies internationally (see Table 6). Most work has been done in the USA and not every study reports

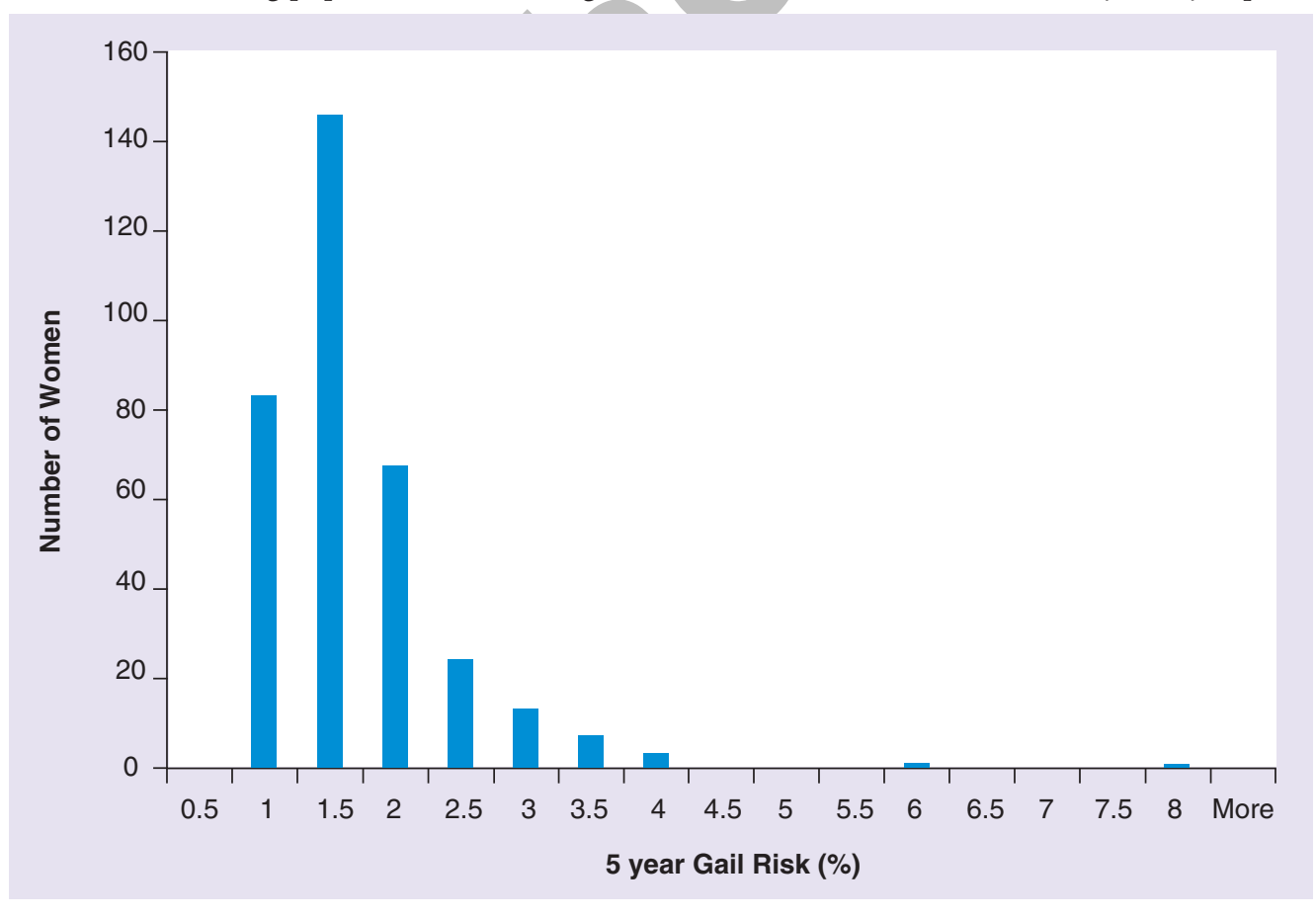

Figure 4. Histogram of the range of 5-year risk scores in the sample. 


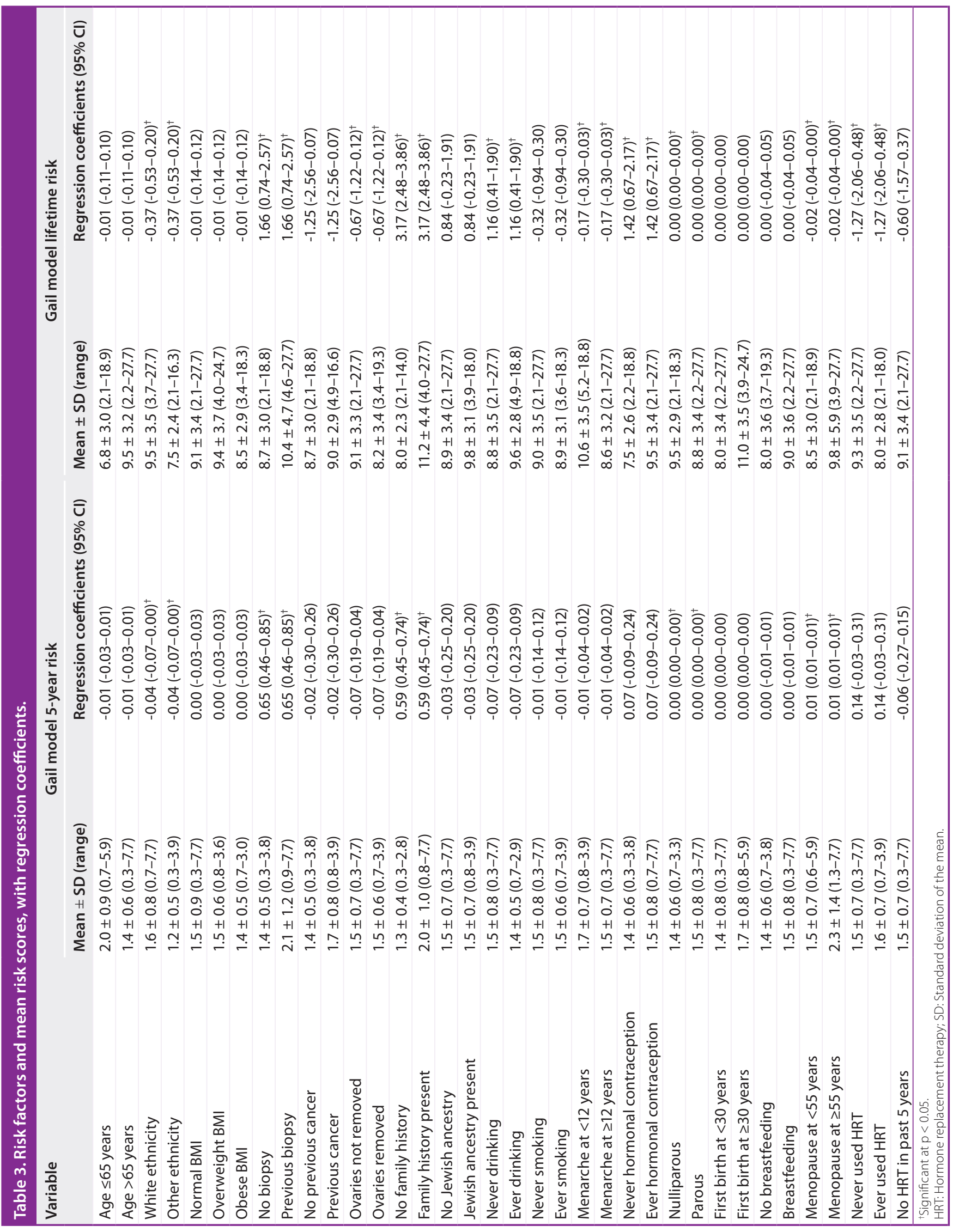




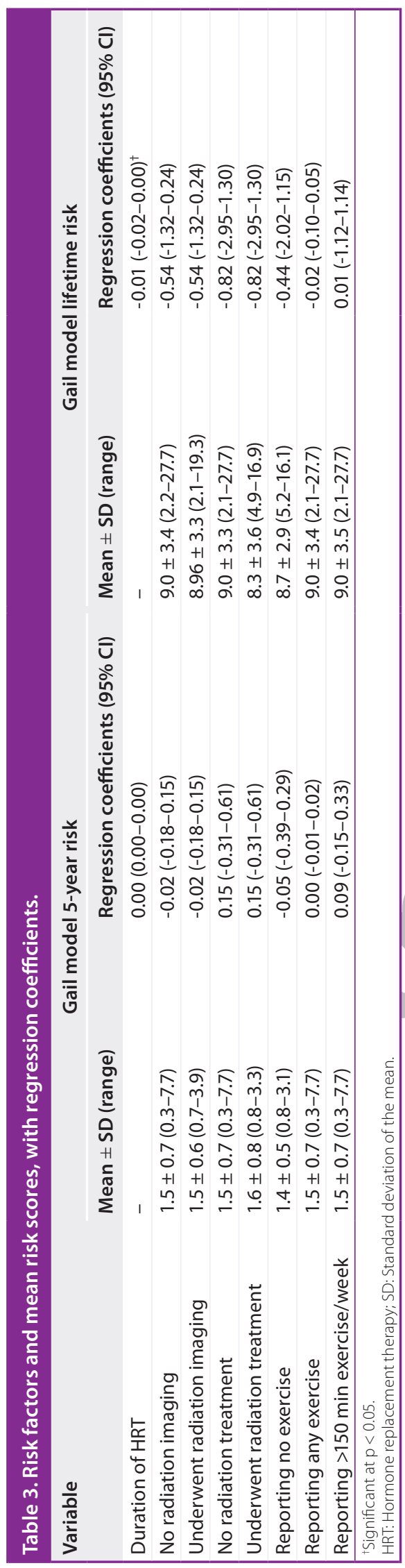

each of the measures of interest, but it can be seen that our results are largely comparable with those from other countries. Our proportion of high-risk 5-year scores is higher than found elsewhere, and that of high-risk lifetime scores is lower. Many of the American programs offer screening to considerably younger women than in the UK, from age 35 onwards, which is likely to change the risk distribution: younger women are likely to have higher lifetime risk scores purely because of the greater age gap to age 90, the point to which the risk of cancer is calculated. The average age of our participants was 56 years (range 46-74 years), which may affect the comparative risk distributions.

In terms of other UK studies, as mentioned previously, there are few that have collected risk factor data from a standard screening population. The PROCAS study did collect risk factor data in a UK screening setting, but used the Tyrer-Cuzick model rather than the Gail model for calculating risk of $\mathrm{BC}$ [28] so the risk scores are not directly comparable. The median 10-year risk reported in PROCAS was $2.7 \%$ (range: 0.8 $24.3 \%$ ). In the PROCAS model, a 10-year risk of $\geq 8 \%$ represents a high risk of $\mathrm{BC}$ and $1.1 \%$ of participants had this level of risk and $8.2 \%$ of women had moderately increased risk (5-8\%). This compares to our proportion of high risk of $27 \%$ within the 5 -year risk model and $0.6 \%$ in the lifetime risk model.

The risk scores calculated in this study were not significantly correlated with the radiologists' decision to recall patients for further assessment. However, this is not necessarily an important outcome, as the decision to recall does not mean the woman has cancer in the majority of cases. Twenty-six women were recalled for further testing in this study. Of these women, one did not return for assessment, nine (35\%) were eventually confirmed to have no abnormality and for $22(85 \%)$ there was no treatment or further action taken. Six women (23\%) had biopsies taken and two were found to have invasive BC and went on to have surgery.

- Risk factors \& the potential for modification

The Gail model 5-year risk scores reported in this study were found to be correlated with various risk factors such as age at menopause and number of pregnancies, with the lifetime risk score significantly correlated with ever drinking or taking hormone-based contraception, ovary 
PRELIMINARY COMMUNICATION Eadie, Enfield, Taylor, Michell \& Gibson

\begin{tabular}{|c|c|}
\hline Finding & Number (\%) \\
\hline Cyst & $6(23)$ \\
\hline Fibroadenoma & $1(4)$ \\
\hline Malignancy & $2(8)$ \\
\hline Calcification & $3(12)$ \\
\hline Lymph node abnormality & $1(4)$ \\
\hline Benign mass & $5(19)$ \\
\hline Asymmetry & $1(4)$ \\
\hline Not abnormal & $9(35)$ \\
\hline
\end{tabular}

removal and duration of HRT. These correlations are not surprising: most are related to hormonal changes and support the literature concerning $\mathrm{BC}$ risk [36]. However, several are modifiable risk factors - variables that are a matter of choice for the woman - and so the level of risk could potentially be altered. It is possible that reducing or stopping drinking or hormonal contraceptive use could have an effect on risk [37,38]. A recent prospective cohort study reported that even low consumption of alcohol of 5 to $9.9 \mathrm{~g}$ per day (3-6 glasses of wine per week) seems to be associated with an increase in BC risk. They reported a $10 \%$ risk increase with each $10 \mathrm{~g}$ per day of alcohol intake, although there was no difference between different types of alcohol seen [39]. Alcohol consumption is a risk factor that can be altered as part of lifestyle changes. In our sample, 23\% reported consuming alcohol at least once a day on average for 6 months or longer, and of these, $11 \%$ were currently still doing so. Another modifiable risk factor is being overweight or obese. While $41 \%$ of our sample was classed as 'healthy', 32\% were overweight and $26 \%$ were obese. It is thought that more than $5 \%$ of all cancers in the UK are linked to being overweight or obese and many studies have linked postmenopausal obesity to BC, such as the Million Women Study [40]. The EPIC study reported that women with a BMI $>30 \mathrm{~kg} / \mathrm{m}^{2}$ had a $31 \%$ excess risk of $\mathrm{BC}$ compared to women with a BMI $<25 \mathrm{~kg} / \mathrm{m}^{2}$ [41]. The BLLISS study specifically looked at lifestyle-related BC risk factors in a UK screening clinic and reported figures similar to those found in our study: 50\% of patients were either obese or overweight and $22 \%$ of patients had a BMI of $>30 \mathrm{~kg} / \mathrm{m}^{2}$ [42]. They also asked women about exercise: $42 \%$ of women performed no exercise and $24 \%$ met the Department of Health guideline of $30 \mathrm{~min}$ of exercise for 5 days a week (now superseded). Our sample fared better: only $7 \%$ reported doing no exercise and $84 \%$ met the new Department of Health guideline of $150 \mathrm{~min}$ of exercise or more per week.

In our study, $44 \%$ of the sample reported smoking, averaging six cigars/cigarettes per day for a mean of 93.5 months. However, the research concerning smoking and BC is less straightforward. Many studies have looked at this topic and there is little agreement, but the most recent research seems to suggest that there may be a causal link between smoking and BC, in particular heavy long-term smoking, and in those who started smoking at an early age [43]. In addition, the effect may be modified by obesity among postmenopausal women, with nonobese women being more affected by smoking-added risk [44].

It certainly seems to be worth reminding women that they can take an active role in changing their health and their risk of breast and other cancers. It has been suggested that up to half of all cancers could be prevented by lifestyle changes [45].

\section{- Implications for clinical practice, research \& policy}

So how can knowledge of BC risk be used in the current BC screening program? In the USA, women at high risk, defined by age, genetics and family history, or Gail model risk score, can be offered MRI screening in addition to mammograms, and even preventative medication such as tamoxifen [35,46]. In England, the Gail model score is not used; BC risk assessment is based on family history of breast or ovarian cancer. National Institute for Clinical Excellence guidelines define moderate and high-risk groups depending on the number of first- and second-degree relatives diagnosed at specific ages [47]. Women are advised to discuss their risk with their GP who may decide to refer them to a specialist genetics service for a detailed assessment. Scottish researchers looked at the outcomes of women who were referred to high-risk clinics, but were then determined to be 'less than moderate risk' and not offered enhanced screening. They found a relative risk of $\mathrm{BC}$ compared to what was expected in this age group of 1.94 [48]. It is possible that taking into consideration a wider range of factors could help to further stratify the risk assessment and therefore the screening of these women who fall in between groups. The current system puts the responsibility for action on the woman, 


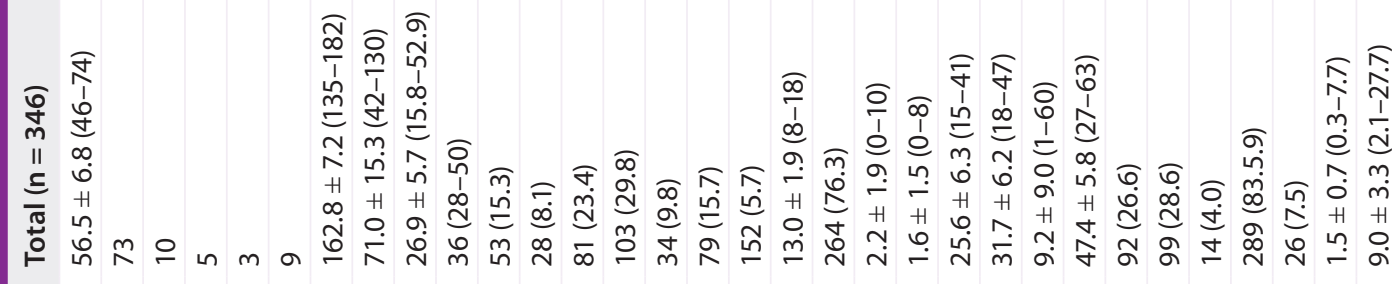

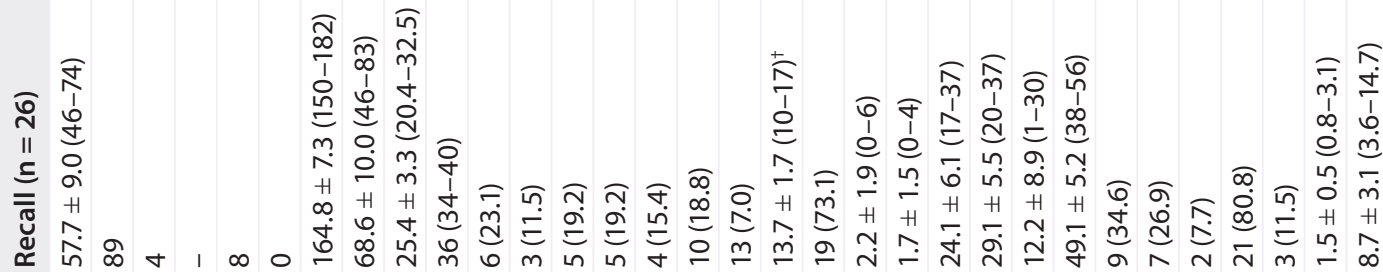

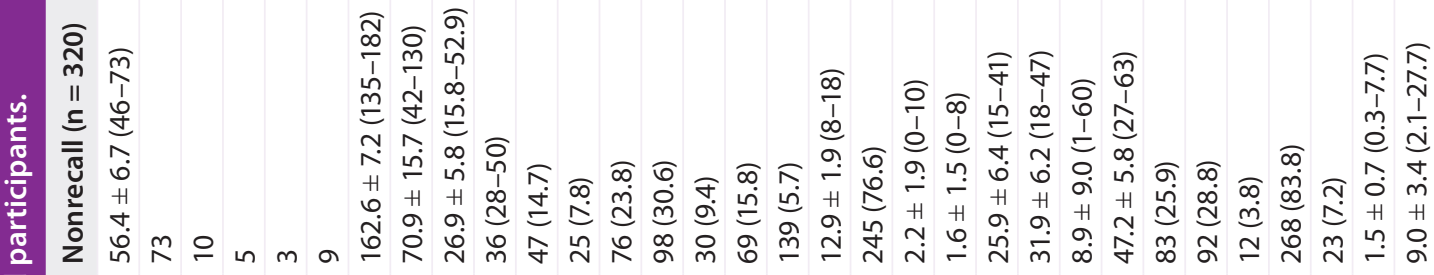

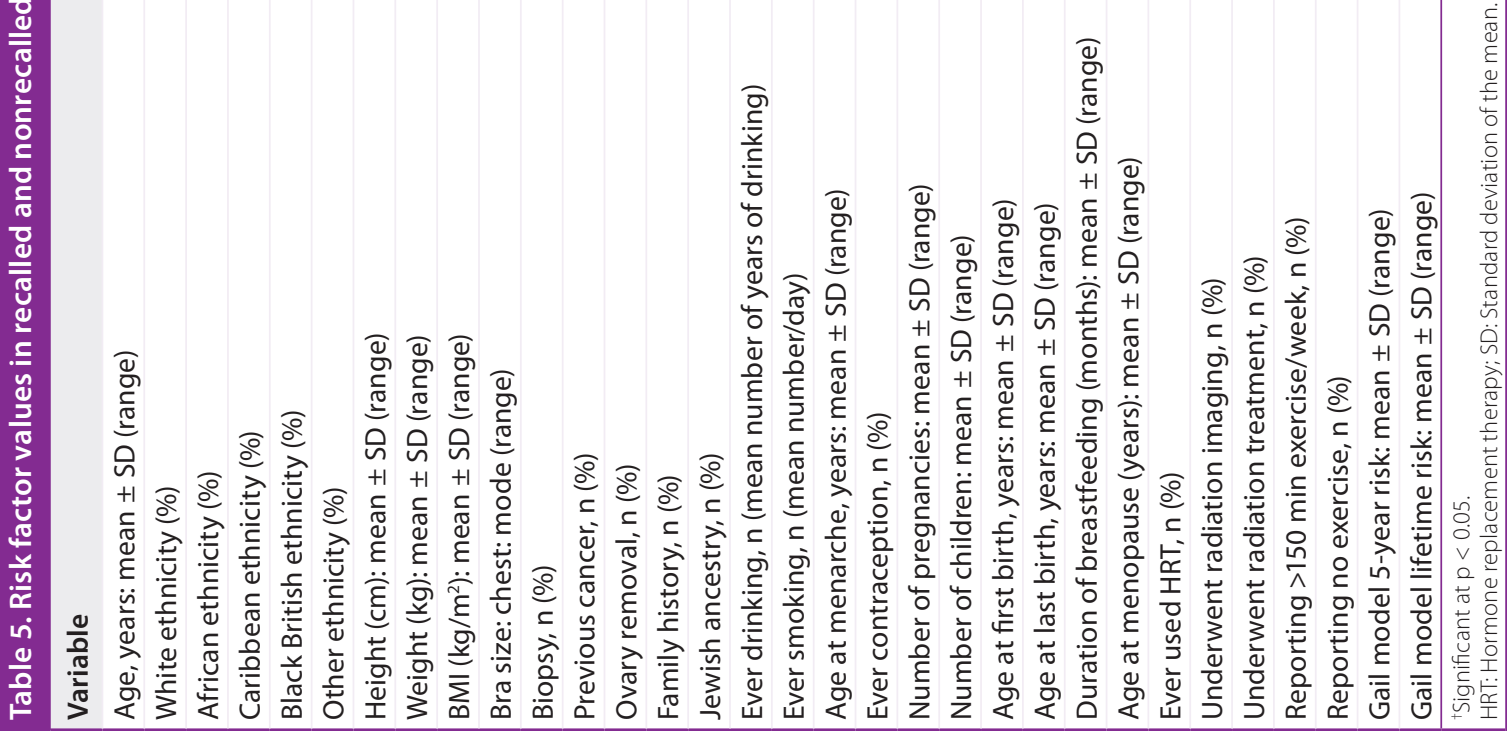


PRELIMINARY COMMUNICATION Eadie, Enfield, Taylor, Michell \& Gibson

\begin{tabular}{|c|c|c|c|c|c|c|}
\hline \multirow[t]{2}{*}{ Study, year (location) } & \multirow[t]{2}{*}{$\mathrm{n}$} & \multicolumn{2}{|c|}{5 -year risk score (\%) } & \multicolumn{2}{|c|}{ Lifetime risk score (\%) } & \multirow[t]{2}{*}{ Ref. } \\
\hline & & Mean & High risk & Mean & High risk & \\
\hline Current study (UK) & 346 & 1.5 & 27 & 9 & 0.6 & ASK \\
\hline Medina-Franco et al. 2004 (Mexico) & 1000 & 1.2 & 25.6 & 9.3 & - & [76] \\
\hline Owens et al. 2011 (USA) & 5718 & - & 14.5 & - & 2.8 & [77] \\
\hline Seyednoori et al. 2012 (Iran) & 314 & 0.8 & 5.1 & 9 & - & [78] \\
\hline Crepeau et al. 2008 (USA) & 110 & - & - & 8 & - & [21] \\
\hline Tam et al. 2010 (Canada) & 416 & 1.7 & - & - & - & [22] \\
\hline Graubard et al. 2010 (USA) & 31,321 & - & - & - & 1.1 & [79] \\
\hline Ulusoy et al. 2010 (Turkey) & $650^{+}$ & 0.94 & 7.7 & - & - & [80] \\
\hline Açıkgöz and Ergör 2013 (Turkey) & 178 & - & 9 & - & - & [81] \\
\hline Pastor-Barriuso et al. 2013 (Spain) $^{\ddagger}$ & 54,649 & 0.95 & 4.1 & - & - & [82] \\
\hline
\end{tabular}

although a BC risk assessment tool for general practitioners has been developed and is undergoing testing in pilot areas [49]. Incorporating risk assessment into primary care could help to raise disease awareness, informing and advising women who may know little about BC risk and would therefore not necessarily consider themselves to be at higher than average risk. Details of modifiable risk factors and the potential for risk reduction can be provided, and screening - and even preventative medication - can be offered to provide more personalized care. When women have knowledge about their personal risk, they can make choices about screening on a more informed and individual basis and take greater responsibility for their own health.

\section{Conclusion}

This article reports on the range of BC risk factors and Gail model scores found in a standard screening population in an inner-city clinic. The results show that risk scores are affected by modifiable risk factors and women may be able to reduce their risk through lifestyle changes.

\section{Future perspective}

There is currently a major initiative in medicine to personalize medicine, partly as a result of the Human Genome Project, and partly from our increasing ability to collect and analyze large amounts of data. The NHS Breast Screening Program currently offers a standard screening protocol to all women, apart from those who are deemed 'high risk' predominantly due to family history. In the next 5-10 years, we expect to see screening become more personalized to the needs of individual patients based on assessment of individual risk factors.

\section{Acknowledgements}

The authors are grateful to the women who participated in the survey, and to the staff at the South East London Breast Screening Service.

Financial \& competing interests disclosure This work was funded by the EPSRC (EP/F01208X/1). The authors have no other relevant affiliations or financial involvement with any organization or entity with a financial interest in or financial conflict with the subject matter or materials discussed in the manuscript apart from those disclosed.

No writing assistance was utilized in the production of this manuscript.

\section{Ethical conduct of research}

The authors state that they have obtained appropriate Institutional Animal Care and Use Committee review board approval or have followed the principles outlined in the Declaration of Helsinki for all human or animal experimental investigations.

\section{References}

Papers of special note have been highlighted as:

- of interest

-1 of considerable interest

1 Independent UK Panel on Breast Cancer Screening. The benefits and harms of breast cancer screening: an independent review. Lancet 380 (9855), 1778-1786 (2012).

- This review of the UK Breast Screening Programme was called for following a debate about the effectiveness of screening mammography and the extent of overdiagnosis, and makes recommendations for clearer information to be provided to women attending screening.

Quanstrum KH, Hayward RA. Lessons from the mammography wars. $N$. Engl. J. Med. 363(11), 1076-1079 (2010). 
3 Elmore J, Choe J. Breast cancer screening for women in their 40s: moving from controversy about data to helping individual women. Ann. Intern. Med. 146(7), 529-531 (2007).

4 IARC Working Group on the Evaluation of Cancer Preventive Strategies. Breast Cancer Screening. In: IARC Handbooks of Cancer Prevention. Vol. 7. IARC Press, Lyon, France (2002).

5 Council of the European Union. Council Recommendation of 2 December 2003 on Cancer Screening (2003/878/EC). OJ L 327. Office for Official Publications of the European Communities (2003).

6 National Health Service Breast Screening Programme. Breast Screening ProgrammeEngland 2010-11. National Statistics, The Information Centre, Sheffield, UK (2012).

7 Prado A, Andrades P, Parada F. Recent developments in the ability to predict and modify breast cancer risk. J. Plast. Reconstr. Aesthet. Surg. 63, 1581-1587 (2010).

8 Gail MH, Brinton LA, Byar DP et al. Projecting individualized probabilities of developing breast cancer for white females who are being examined annually. J. Natl Cancer Inst. 81, 1879-1886 (1989).

- Describes the original Gail model for estimating risk of breast cancer. Although various flaws have been described since its creation, this is still an important paper showing the process of developing and testing a risk model.

9 Barlow WE, White E, Ballard-Barbash R et al. Prospective breast cancer risk prediction model for women undergoing screening mammography. J. Natl Cancer Inst. 98, 1204-1214 (2006).

10 Claus EB, Risch N, Thompson WD Autosomal dominant inheritance of early-onset breast cancer implications for risk prediction. Cancer 73(3), 643-651 (1994).

11 Tyrer J, Duffy SW, Cuzick J. A breast cancer prediction model incorporating familial and personal risk factors. Stat. Med. 23, 1111-1130 (2004).

- Describes the Tyrer-Cuzick risk assessment model, which provides a method of estimating a woman's likelihood of possessing a gene connected to breast cancer based on their family history.

12 Wacholder S, Hartge P, Prentice R et al. Performance of common genetic variants in breast-cancer risk models. N. Engl. J. Med. 362, 986-993 (2010).

13 Meads C, Ahmed I, Riley RD. A systematic review of breast cancer incidence risk prediction models with meta-analysis of their performance. Breast Cancer Res. Treat. 132(2), 365-377 (2012).

- Assesses the numerous breast cancer risk calculation models, their reporting, and the success in prediction observed. A good read for those interested in risk models.

14 Amir E, Freedman OC, Seruga B, Evans DG. Assessing women at high risk of breast cancer: a review of risk assessment models. J. Natl Cancer Inst. 102, 680-691 (2010).

15 Ready K, Litton JK, Arun BK. Clinical application of breast cancer risk assessment models. Fut. Oncol. 6(3), 355-365 (2010).

16 Schonfeld SJ, Pee D, Greenlee RT et al. Effect of changing breast cancer incidence rates on the calibration of the Gail Model. J. Clin. Oncol. 28(14), 2411-2417 (2010).

17 Newman LA. Applicability of the Gail model for breast cancer risk assessment in Turkish female population and evaluation of breastfeeding as a risk factor. Breast Cancer Res. Treat. 120(2), 425-426 (2010).

18 Amir E, Evans DG, Shenton A et al. Evaluation of breast cancer risk assessment packages in the family history evaluation and screening programme. J. Med. Genet. 40(11), 807-814 (2003).

19 Anothaisintawee T, Teerawattananon $\mathrm{Y}$, Wiratkapun C, Kasamesup V, Thakkinstian A. Risk prediction models of breast cancer: a systematic review of model performances. Breast Cancer Res. Treat. 133(1), 1-10 (2012).

20 Darabi H, Czene K, Zhao W, Liu J, Hall P, Humphreys K. Breast cancer risk prediction and individualised screening based on common genetic variation and breast density measurement. Breast Cancer Res. 14(1), R25 (2012).

21 Crepeau AZ, Willoughby L, Pinsky B, Hinyard L, Shah M. Accuracy of personal breast cancer risk estimation in cancer-free women during primary care visits. Women Health 47(2), 113-130 (2008).

22 Tam CY, Martin LJ, Hislop G, Hanley AJ, Minkin S, Boyd NF. Risk factors for breast cancer in postmenopausal Caucasian and Chinese-Canadian women. Breast Cancer Res. 12(1), R2 (2010).

23 Ali AMG, Greenberg D, Wishart GC, Pharoah P. Patient and tumour characteristics, management, and age-specific survival in women with breast cancer in the East of England. Br. J. Cancer 104, 564-570 (2011).

24 Brewster DH, Clark DI, Stockton DL, Munro AJ, Steele RJ. Characteristics of patients dying within 30 days of diagnosis of breast or colorectal cancer in Scotland, 2003-2007. Br. J. Cancer 104(1), 60-67 (2011).

25 Bansal N, Bhopal RS, Steiner MF, Brewster DH. Scottish Health and Ethnicity Linkage Study. Major ethnic group differences in breast cancer screening uptake in Scotland are not extinguished by adjustment for indices of geographical residence, area deprivation, long-term illness and education. Br. J. Cancer 106(8), 1361-1366 (2012).

26 Renshaw C, Jack RH, Dixon S, Møller H, Davies EA. Estimating attendance for breast cancer screening in ethnic groups in London. BMC Public Health 10, 157 (2010).

27 Banks E, Beral V, Cameron R et al. Comparison of various characteristics of women who do and do not attend for breast cancer screening. Breast Cancer Res. 4(1), R1 (2002)

28 Evans DG, Warwick J, Astley SM et al. Assessing individual breast cancer risk within the U.K. National Health Service Breast Screening Program: a new paradigm for cancer prevention. Cancer Prev. Res. (Phila.) 5(7), 943-951 (2012).

- Describes an ambitious plan to gather hormonal, lifestyle and genetic information from screening populations in Manchester, UK, and link it to mammographic estimations of breast density in order to form a comprehensive assessment of breast cancer risk. We look forward to seeing the results.

29 Gail MH, Costantino JP, Pee D et al. Projecting individualized absolute invasive breast cancer risk in African American women. J. Natl Cancer Inst. 99(23), 1782-1792 (2007).

30 Matsuno RK, Costantino JP, Ziegler RG et al. Projecting individualized absolute invasive breast cancer risk in Asian and Pacific Islander American women. J. Natl Cancer Inst. 103(12), 951-961 (2011).

31 National Institute for Health and Clinical Excellence. Obesity: guidance on the prevention, identification, assessment and management of overweight and obesity in adults and children. NICE Clin. Guideline 43 (2006).

32 American Cancer Society. Breast Cancer Facts \& Figures 2011-2012. American Cancer Society, Inc., GA, USA (2012).

33 The Office for National Statistics. Cancer Incidence and Mortality in the United Kingdom, 2008-10. Table 6: Directly age-standardised registration rates with 95 per cent confidence intervals per 100,000 population of newly diagnosed cases of cancer: Selected sites by sex and country, United Kingdom, 2008-2010. 
The Office for National Statistics, Newport, New South Wales, Austrailia (2012).

34 The Office for National Statistics. Cancer Registration Statistics, England, 2011. Table 4: Directly age-standardised rates per 100,000 population of newly diagnosed cases of cancer (3rd digit): site, sex and region of residence, England, 2011. The Office for National Statistics, Newport, New South Wales, Austrailia (2013).

35 Fisher B, Costantino JP, Wickerham L et al. Tamoxifen for prevention of breast cancer: report of the National Surgical Adjuvant Breast and Bowel Project P-1 Study. J. Natl Cancer Inst. 90, 1371-1388 (1998).

36 ESHRE Capri Workshop Group. Hormones and breast cancer. Hum. Reprod. Update 10 (4), 281-293 (2004).

37 Baan R, Straif K, Grosse Y et al. Carcinogenicity of alcoholic beverages. Lancet Oncol. 8(4), 292-293 (2007).

38 Collaborative Group on Hormonal Factors in Breast Cancer. Breast cancer and hormonal contraceptives: collaborative reanalysis of individual data on 53,297 women with breast cancer and 100,239 women without breast cancer from 54 epidemiological studies. Lancet 347(9017), 1713-1727 (1996).

39 Chen WY, Rosner B, Hankinson SE, Colditz GA, Willett WC. Moderate alcohol consumption during adult life, drinking patterns, and breast cancer risk. JAMA 306(17), 1884-1890 (2011).

40 Reeves GK, Pirie K, Beral V et al. Cancer incidence and mortality in relation to body mass index in the Million Women Study cohort study. BMJ 335(7630), 1134 (2007).

41 Lahmann PH, Hoffmann K, Allen $\mathrm{N}$ et al. Body size and breast cancer risk: findings from the European Prospective Investigation into Cancer and Nutrition (EPIC). Int. J. Cancer 111(5), 762-771 (2004).

42 Carmichael AR, Harbach L, Cooke R. Breast clinic and life style study BLLISS. Int. Semin. Surg. Oncol. 6, 12 (2009).

43 Reynolds P. Smoking and breast cancer. J. Mammary Gland Biol. Neoplasia 18(1), 15-23 (2013).

44 Luo J, Horn K, Ockene JK et al. Interaction between smoking and obesity and the risk of developing breast cancer among postmenopausal women: the Women's Health Initiative Observational Study. Am. J. Epidemiol. 174(8), 919-928 (2011).

45 Parkin DM, Boyd L, Walker LC. 16: The fraction of cancer attributable to lifestyle and environmental factors in the UK in 2010:
Summary and conclusions. Br. J. Cancer 105, S77-S81 (2011).

46 Saslow D, Boetes C, Burke W et al. American Cancer Society guidelines for breast screening with MRI as an adjunct to mammography. CA Cancer J. Clin. 57, 75-89 (2007).

47 National Institute for Health and Clinical Excellence. The classification and care of women at risk of familial breast cancer in primary, secondary and tertiary care. NICE Clin. Guideline 41 (2006).

48 Anderson E, Berg J, Black R et al. Prospective surveillance of women with a family history of breast cancer: auditing the risk threshold. Br. J. Cancer 98(4), 840-844 (2008).

49 UK Department of Health. Improving Outcomes: A Strategy for Cancer UK Department of Health, London, UK (2011).

50 Hamajima N, Hirose K, Tajima K et al. Alcohol, tobacco and breast cancercollaborative reanalysis of individual data from 53 epidemiological studies, including 58,515 women with breast cancer and 95,067 women without the disease. Br.J. Cancer 87 1234-1245 (2002).

51 Egan KM, Newcomb PA, Longnecker MP et al. Jewish religion and risk of breast cancer. Lancet 347(9016), 1645-1646 (1996).

52 Baer HJ, Rich-Edwards JW, Colditz GA, Hunter DJ, Willett WC, Michels KB. Adult height, age at attained height, and incidence of breast cancer in premenopausal women. Int. J. Cancer 119(9), 2231-2235 (2006).

53 Key T, Appleby P, Barnes I, Reeves G, Endogenous Hormones and Breast Cancer Collaborative Group. Endogenous sex hormones and breast cancer in postmenopausal women: reanalysis of nine prospective studies. J. Natl Cancer Inst. 94(8), 606-616 (2002)

54 Nelson CL, Sellers TA, Rich SS, Potter JD, McGovern PG, Kushi LH. Familial clustering of colon, breast, uterine, and ovarian cancers as assessed by family history. Genet. Epidemiol. 10(4), 235-244 (1993).

55 Pfeiffer RM, Park Y, Kreimer AR et al. Risk prediction for breast, endometrial, and ovarian cancer in white women aged $50 \mathrm{y}$ or older: derivation and validation from population-based cohort studies. PLoS Med. 10(7), e1001492 (2013)

56 Collaborative Group on Hormonal Factors in Breast Cancer. Menarche, menopause, and breast cancer risk: individual participant meta-analysis, including 118,964 women with breast cancer from 117 epidemiological studies. Lancet Oncol. 13(11), 1141-1151 (2012).
57 Brinton LA, Schaiere C, Hoover RN et al. Menstrual factors and risk of breast cancer. Cancer Invest. 6, 145-154 (1988).

58 Cibula D, Gompel A, Mueck AO et al. Hormonal contraception and risk of cancer. Hum. Reprod. Update 16(6), 631-650 (2010).

59 Carter CL, Jones DY, Schatzkin A, Brinton LA. A prospective study of reproductive, familial and socioeconomic risk factors for breast cancer using NHANES I data. Public Health Rep. 104(1), 45-50 (1989).

60 White E. Projected changes in breast cancer incidence due to the trend toward delayed childbearing. Am. J. Public Health 77, 495-497 (1987)

61 Collaborative Group on Hormonal Factors in Breast Cancer. Breast cancer and breastfeeding: collaborative reanalysis of individual data from 47 epidemiological studies in 30 countries, including 50302 women with breast cancer and 96973 women without the disease. Lancet 360(9328), 187-195 (2002).

62 Eliassen AH, Colditz GA, Rosner B, Willett WC, Hankinson SE. Adult weight change and risk of postmenopausal breast cancer. JAMA 296(2), 193-201 (2006).

63 Bakken K, Fournier A, Lund E et al. Menopausal hormone therapy and breast cancer risk: impact of different treatments. The European Prospective Investigation into Cancer and Nutrition. Int. J. Cancer 128(1), 144-156 (2011).

64 Ganry O, Baudoin C, Fardellone P, Peng J, Raverdy N. Bone mass density and risk of breast cancer and survival in older women. Eur. J. Epidemiol. 19(8), 785-792 (2004).

65 Sattin RW, Rubin GL, Webster LA et al. Family history and the risk of breast cancer. JAMA 253(13), 1908-1913 (1985).

66 Collaborative Group on Hormonal Factors in Breast Cancer. Familial breast cancer: collaborative reanalysis of individual data from 52 epidemiological studies including 58,209 women with breast cancer and 101,986 women without the disease. Lancet 358(9291), 1389-1399 (2001).

67 Howlader N, Noone AM, Krapcho M et al. SEER Cancer Statistics Review, 1975-2010, National Cancer Institute. MD, USA (2013).

68 Chen S, Iversen ES, Friebel T et al. Characterization of BRCA1 and BRCA2 mutations in a large United States sample. J. Clin. Oncol. 24(6), 863-871 (2006).

69 McCormack VA, dos Santos Silva I. Breast density and parenchymal patterns as markers of breast cancer risk: a meta-analysis. Cancer Epidemiol. Biomarkers Prev. 15(6), 1159-1169 (2006). 


\section{Breast cancer risk scores in a standard screening population PRELIMINARY COMMUNICATION}

70 Dupont WD, Park FF, Hartmann WH et al. Breast cancer risk associated with proliferative breast disease and atypical hyperplasia. Cancer 71, 1258-1265 (1993).

71 Hartmann LC, Sellers TA, Frost MH et al. Benign breast disease and the risk of breast cancer. N. Engl. J. Med. 353, 229-237 (2005).

72 Hankey BG, Curtis RE, Naughton MD et al. A retrospective cohort analysis of second breast cancer risk for primary breast cancer patients with an assessment of the effect of radiation therapy. J. Natl Cancer Inst. 70, 797-804 (1983).

73 Dores GM, Anderson WF, Beane Freeman LE, Fraumeni JF Jr, Curtis RE. Risk of breast cancer according to clinicopathologic features among long-term survivors of Hodgkin's lymphoma treated with radiotherapy. $B r$. J. Cancer 103(7), 1081-1084 (2010).

74 Boice JD Jr, Preston D, Davis FG, Monson $R R$. Frequent chest $\mathrm{X}$-ray fluoroscopy and breast cancer incidence among tuberculosis patients in Massachusetts. Radiat. Res. 125(2), 214-222 (1991).

75 Shore RE, Hildreth N, Woodard E, Dvoretsky P, Hempelmann L, Pasternack B. Breast cancer among women given $\mathrm{X}$-ray therapy for acute postpartum mastitis. J. Natl Cancer Inst. 77(3), 689-696 (1986).

76 Medina-Franco H, Garza E, Gabilondo B, Gaona-Luviano P. Risk of invasive breast cancer in Mexican population and patterns of screening and prophylaxis. Rev. Invest. Clin. 56(4), 422-426 (2004)

77 Owens WL, Gallagher TJ, Kincheloe MJ, Ruetten VL. Implementation in a large health system of a program to identify women at high risk for breast cancer. J. Oncol. Pract. 7(2), 85-88 (2011).

78 Seyednoori T, Pakseresht S, Roushan Z. Risk of developing breast cancer by utilizing Gail model. Women Health 52 (4), 391-402 (2012).

79 Graubard BI, Freedman AN, Gail MH. Five-year and lifetime risk of breast cancer among U.S. subpopulations: implications for magnetic resonance imaging screening. Cancer Epidemiol. Biomarkers Prev. 19(10), 2430-2436 (2010).

80 Ulusoy C, Kepenekci I, Kose K, Aydintug S, Cam R. Applicability of the Gail model for breast cancer risk assessment in Turkish female population and evaluation of breastfeeding as a risk factor. Breast Cancer Res. Treat. 120(2), 419-424 (2010).

81 Açıkgöz A, Ergör G. Compliance with screening recommendations according to breast cancer risk levels in Izmir, Turkey. Asian Pac. J. Cancer Prev. 14(3), 1737-1742 (2013).

82 Pastor-Barriuso R, Ascunce N, Ederra $\mathrm{M}$ et al. Recalibration of the Gail model for predicting invasive breast cancer risk in Spanish women: a population-based cohort study. Breast Cancer Res. Treat. 138(1), 249-259 (2013).

\section{- Websites}

101 NHS Breast Screening Programme. www.cancerscreening.nhs.uk/breastscreen/ index.html

102 The Million Women Study. www.millionwomenstudy.org

103 National Cancer Institute Breast Cancer Risk Assessment Tool. www.cancer.gov/bcrisktool/

104 WHO Global Database on BMI Classification. apps.who.int/bmi/index. jsp?introPage $=$ intro_3.htmlDepartment of Health Physical activity guidelines for adults.

www.nhs.uk/Livewell/fitness/Pages/ physical-activity-guidelines-for-adults.aspx

105 American Cancer Society recommendations for early breast cancer detection in women without breast symptoms. www.cancer.org/cancer/breastcancer/ moreinformation/breastcancerearlydetection/ breast-cancer-early-detection-acs-recs

106 Office for National Statistics. Neighbourhood Statistics, May 2011. neighbourhood.statistics.gov.uk 